\title{
An Intelligent Coordinator Design for GCSC and AGC in a Two-area Hybrid Power System
}

\author{
Rahmat Khezri ${ }^{1}$, Arman Oshnoei ${ }^{2}$, Soroush Oshnoei ${ }^{2}$, Hassan Bevrani ${ }^{3}$, SM Muyeen $^{4}$ \\ ${ }^{1}$ College of Science and Engineering, Flinders University, Adelaide, Australia \\ ${ }^{2}$ Faculty of Electrical and Computer Engineering, Shahid Beheshti University, Tehran, Iran \\ ${ }^{3}$ Department of Electrical and Computer Engineering, University of Kurdistan, Sanandaj, Iran \\ ${ }^{4}$ Department of Electrical and Computer Engineering, Curtin University, Perth, WA, Australia \\ *Corresponding Author: Rahmat Khezri, khezri @ieee.org
}

Abstract- This study addresses the design procedure of an optimized fuzzy fine-tuning (OFFT) approach as an intelligent coordinator for gate controlled series capacitors (GCSC) and automatic generation control (AGC) in hybrid multi-area power system. To do so, a detailed mathematical formulation for the participation of GCSC in tie-line power flow exchange is presented. The proposed OFFT approach is intended for valid adjustment of proportional-integral controller gains in GCSC structure and integral gain of secondary control loop in the AGC structure. Unlike the conventional classic controllers with constant gains that are generally designed for fixed operating conditions, the outlined approach demonstrates robust performance in load disturbances with adapting the gains of classic controllers. The parameters are adjusted in an online manner via the fuzzy logic method in which the sine cosine algorithm subjoined to optimize the fuzzy logic. To prove the scalability of the proposed approach, the design has also been implemented on a hybrid interconnected two-area power system with nonlinearity effect of governor dead band and generation rate constraint. Success of the proposed OFFT approach is established in three scenarios by comparing the dynamic performance of concerned power system with several optimization algorithms including artificial bee colony algorithm, genetic algorithm, improved particle swarm optimization algorithm, ant colony optimization algorithm and sine cosine algorithm. 
Keywords- automatic generation control, gate controlled series capacitors, optimization algorithms, optimized fuzzy based fine tuning, two-area power system.

\section{Introduction}

Imbalances between electric supply and demand can leading up frequency deviations. Generation units try to restore the frequency to the scheduled value after disturbances by regulation of their active power output [1]. This is done by two frequency control loops on conventional generation units known as primary and secondary loops. Contribution through governor of generators is known as the primary frequency control loop. Returning steady state frequency to an acceptable range is not applicable using the primary loop merely. To fill this technical gap, a secondary frequency control loop known as load frequency control (LFC) is added to power systems.

In power system dynamics realm, LFC is the most significant ancillary service for achieving reliable and satisfactory operation. LFC is generally regarded as a major function of automatic generation control (AGC) and it is responsible for frequency regulation in a specified area and affecting the neighboring areas through the interconnected tie-lines [2]. In other words, LFC acquires a fundamental role to enable power exchanges and provide better conditions for electricity trading and it is becoming more significant in recent decade due to changing structure and complexity of interconnected power systems, size increasing in multi-area systems, emerging new uncertainties, and occurrence of various disturbances which could causing momentary and permanent interruptions and even power system blackouts [3]. Due to such challenges, contribution of photovoltaic systems [4], wind turbines [5], energy storages [6], demand response [7], and flexible ac transmission systems (FACTS) devices [8], is recently reported in the LFC of multi-area power systems. In most of the cases, a proportional-integral 
(PI) controller is used as the controller in the LFC structure of components. Tie-line power control is an important role of LFC. Since series FACTS devices are directly connected to the tie-line (interconnection line between areas) with an efficient controllability, they are known as one of the effective devices to contribute in LFC among the other choices.

Literature survey testifies that several studies have been carried out about various LFC issues, in particular, application of FACTS devices (which is the main topic in this paper) to tackle the LFC problem in power systems. Due to more flexibility, effective operational behavior and fast dynamic responses of FACTS, not only the power transfer capability of transmission lines can be released, but also the stability of power system can be enhanced. Series FACTS devices such as thyristor-controlled series capacitor (TCSC) $[8,10,13,17,18,19]$, thyristor controlled phase shifter (TCPS) [14, 20, 22], gate controlled series capacitor (GCSC) [15], static synchronous series compensator (SSSC) [9, 14], unified power flow controller (UPFC) [12, 21], and inter-line power flow controller (IPFC) $[11,16]$ have been studied to mitigate frequency and tie-line power variations and improve the transient response in multi-area power systems. One kind of new series FACTS, known as GCSCs, recently attracted a lot of attentions in power system dynamics for control purposes. Compared to other FACTS devices such as TCSC, the GCSC has the advantages of smaller size of the capacitor, more affordable, higher compensation capability and performance. Moreover, the comparison of GCSC with SSSC proves that the cost and complexity of the GCSC are much less than SSSC [24-26].

As stated, many research works have been published on designing load frequency controller by incorporating FACTS devices. A comprehensive review of the published papers is summarized in Table 1. This Table has considered various aspects of FACTS devices application in LFC problem which can be divided into three main groups: $A$ ) power system configuration, $B$ ) control approach, and $c$ ) soft computing techniques. 
Table 1. Calssification of FACTS contribution in LFC

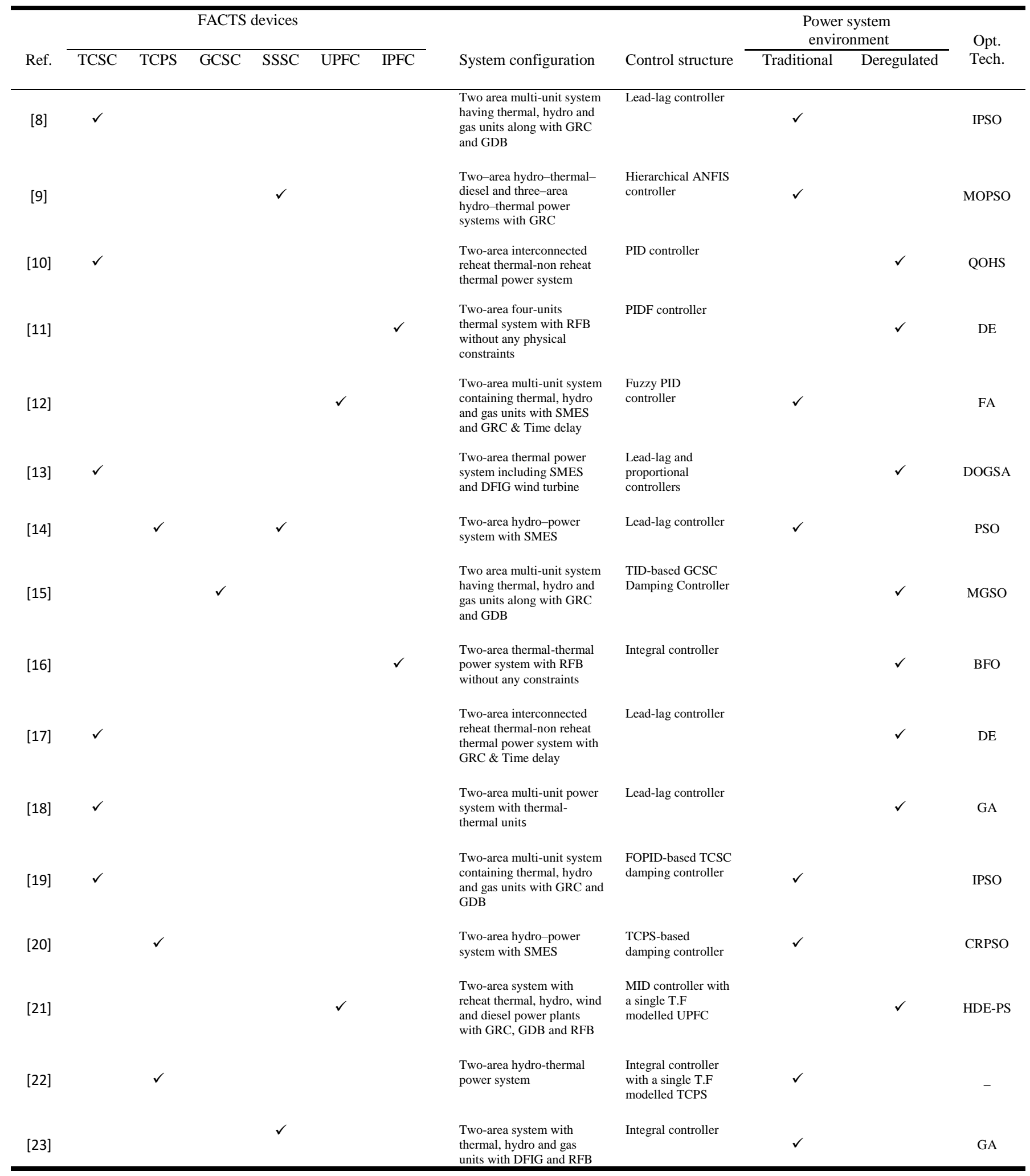

ANFIS: Adaptive Neuro Fuzzy Inference System, PID: Proportional-Integral-Differential, PIDF: PID with Filter, SMC: Sliding Mode Control, MID: Modified Integral Derivative 


\section{A. Power System Configuration}

Traditional power system is mainly composed of conventional generation units such as hydro, thermal, diesel, natural gas, nuclear power, etc. A comprehensive review of published papers related to different structures of power system models for the LFC problem is summarized in $[27,28]$. According to Table 1, participation of FACTS devices in AGC task is mainly implemented on interconnected two area power systems [8-23]. Also, some researchers have investigated the performance improvement of combined AGC-FACTS system in the presence of doubly fed induction generator (DFIG) wind turbine [13, 23], energy storage (ES) elements like superconducting magnetic ES (SMES) [12-14, 20] and redox flow batteries (RFB) $[11,16,21,23]$. As well, in most studies, the effects of nonlinear constraints such as generation

rate constraint (GRC) nonlinearity $[8,9,12,15,17,19,21]$, governor dead-band (GDB) [8, 15, $19,21]$ and time delay $[12,17]$ in signal processing are also considered.

\section{B. Control Approach}

Major number of research works are conducted on control methodologies like adaptive control, self-tuning control, robust control and intelligent control methods for solving the LFC problem in power systems. On the other hand, different models are used in the design of FACTSbased damping controllers in order to mitigate the frequency and tie-line power deviations. Generally, two kind of structures have been utilized for modeling the FACTS devices in literature; one is based-on a single transfer function (TF) $[10-14,16-18,20-23]$ and the other is based-on three TF blocks connected consecutive including two lead-lag blocks [8, 9]. Furthermore, review of the latest papers demonstrates the utilization of fractional order controllers (FOC) like tilt-integral-derivative (TID) controller [15] and fractional order proportional-integral-derivative (FOPID) controller [19] in the FACTS devices, which are more favorable in dynamic response enhancement. 


\section{Soft Computing Techniques}

The advent of various soft computing techniques as a control strategy for searching the global optimal set of adjustable parameters has received much attention in the literature. In [8], the authors have proposed an improved particle swarm optimization (IPSO) algorithm in tuning of the integral gains of AGC and TCSC parameters through minimizing the integral of time multiplied squared error (ITSE) integral performance index. In [19], the same authors reused this algorithm for the FOPID controller in the TCSC damping controller. The tuning feasibility and superiority of modified group search optimization (MGSO) algorithm for AGC application of GCSC is demonstrated in [15]. In [9], multi objective PSO has been proposed to solve the optimization problem owing to high performance of this approach to unravel the non-linear objectives. The results obtained by [10] demonstrate the robustness of quasi-oppositional harmony search (QOHS) algorithm in comparison with other techniques like genetic algorithm (GA) which is employed by the authors in [19] and [23] for the LFC problem. In [11] and [17], the authors have proposed differential evolution (DE) algorithm to optimize different parameters of the damping controllers. Supremacy and robustness of disrupted oppositional learned gravitational search algorithm (DOGSA) for LFC problem including TCSC, SMES and DFIG has been investigated in [13]. The bacterial foraging optimization (BFO) algorithm in [16] has been proposed to adjust the integral gains of the Load-frequency controller. The authors in [21] have proposed a hybrid optimization method namely hybrid DE-pattern search (HDE-PS) for optimizing modified integral derivative controller in the LFC, and they have shown its superiority over GA and DE techniques.

Based-on our scientific information and with the review of papers summarized in Table 1, application of the GCSC as a damping controller for LFC problem in multi-area power systems has been reported only by [15] and it needs further investigations. So, in the present work, the 
performance of GCSC along with the AGC loop known as secondary loop is considered. On the other hand, although designing of fuzzy logic controller is a well-researched topic in the LFC problem, the design of this controller in a combined manner with optimization algorithm for simultaneous online control of FACTS-based controllers and secondary loop of frequency control is not considered in the literature. In the proposed model, a fuzzy fine tuning approach is proposed for GCSC and secondary loop of frequency control in which the sine cosine algorithm (SCA) (as a novel algorithm for optimization problems) has been utilized to optimize the scaling factors in inputs and outputs of fuzzy controller. The optimized fuzzy fine tuning (OFFT) approach has been utilized in an interconnected two-area power system, including thermal, hydro and gas generation units in each control area with GDB and GRC as a perfect model of power systems. The proposed OFFT approach as an intelligent approach is supplemented to the PIbased GCSC damping controller and integral controller of the secondary control loop as the AGC structure which performs an online tuning of the proportional and integral parameters. The superiority of the proposed OFFT approach is established by comparing the dynamic performance with those obtained by powerful optimization techniques: artificial bee colony (ABC), ant colony optimization (ACO), GA, SCA and IPSO.

The remainder of this paper is arranged as follows: the understudy LFC system model and linearized model of GCSC are demonstrated in section 2. Section 3 addresses the objective function formulation for utilizing the optimization algorithms. Also, the employed heuristic optimization methods are described in section 4. The design manner of the proposed OFFT is discussed in section 5. Section 6 demonstrates and investigates the simulation results and the conclusion finalized the paper in section 7.

\section{Load Frequency Control System Modeling}

\subsection{Interconnected Two-Area Power System}


The studied power system model is a hybrid interconnected two-area power grid, containing thermal, hydro and gas units in each control area. The areas are connected via tie-line, which is responsible for power exchange between them. In spite of complicated and nonlinear model of power systems, a simplified and linear simulation model can satisfy the analysis of the frequency performance. In this regard, the schematic of linearized considered power system equipped with the GCSC is illustrated in Fig. 1. The parameters description is given in Nomenclature and their values are available in [7]. To obtain precise and realistic simulation results, the effects of nonlinear constraints such as generation rate constraint (GRC) and governor dead-band (GDB) are included in the model. The GDB is defined as the total magnitude of a sustained speed change, considering that there is no change in valve position of the turbine. The GDB of the backlash type can be linearized in terms of change and the rate of change in the speed. The Fourier coefficients of $N_{1}$ and $N_{2}$ in the GDB transfer function model are selected as $N_{l}=0.8$ and $N_{2}=-0.2 / \pi$ [29]. In practice, the rate of active power change, which can be achieved by thermal and hydro units, has a maximum limit [30]. So, the designed LFC for the unconstrained generation rate situation may not be suitable and realistic. The appropriate GRC of $10 \%$ per minute for thermal unit is considered for both raising and falling rates. For the hydro unit, typical GRC of $270 \%$ per minute for raising generation and $360 \%$ per minute for falling generation are considered [31]. 


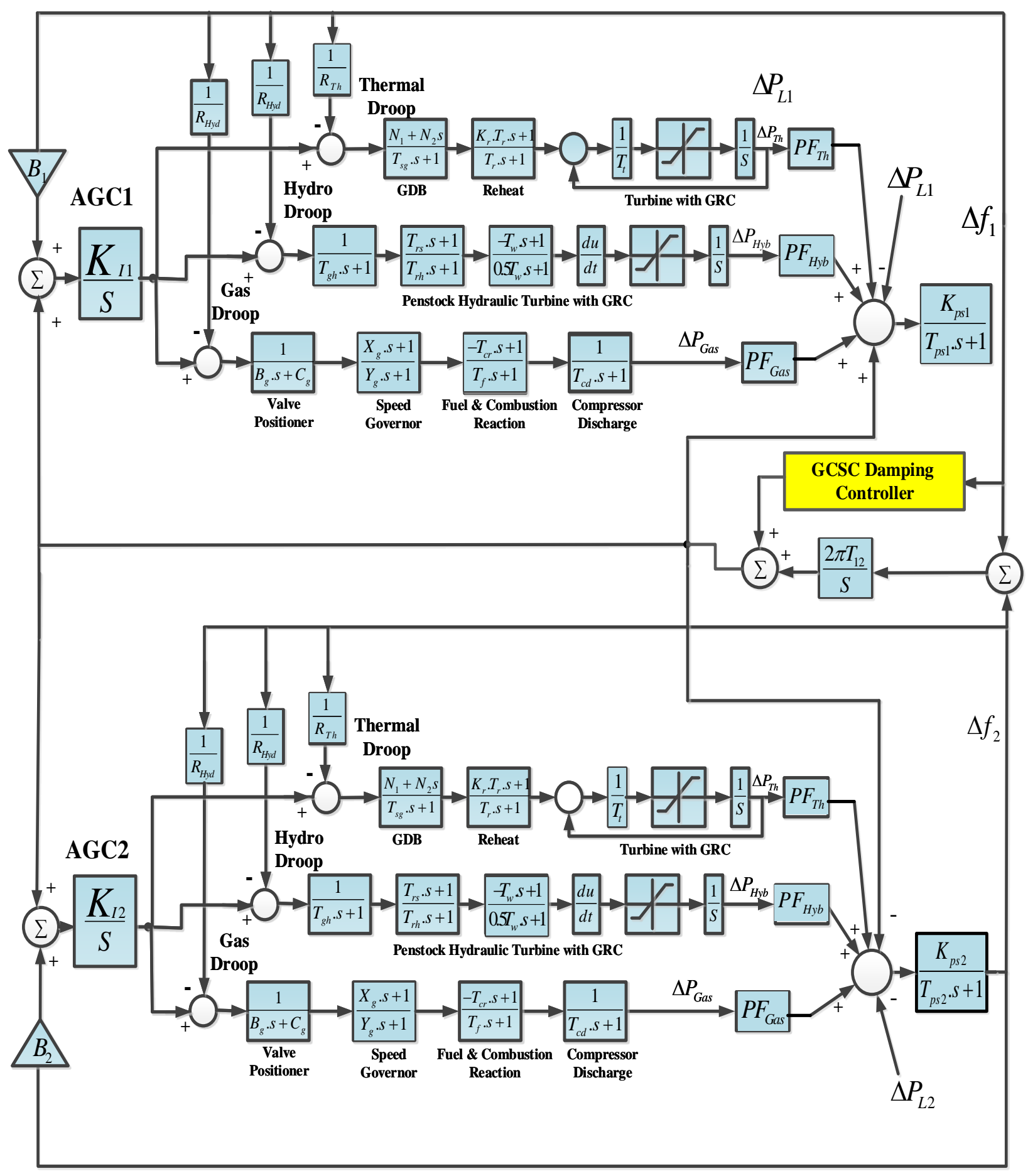

Fig. 1.The linearized TF-based model of two area power system 


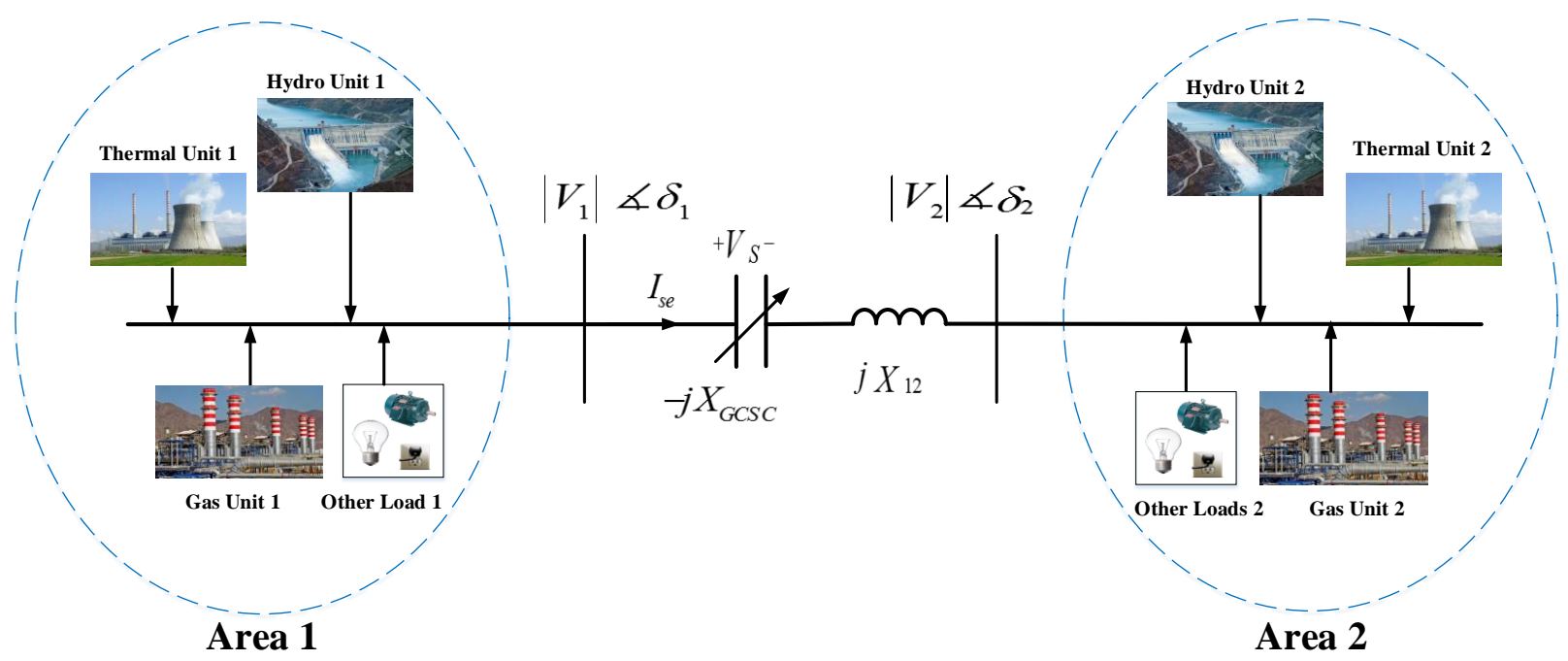

Fig. 2. Schematic diagram of interconnected two-area power system with GCSC

\subsection{Linearized model of gate controlled series capacitors applicable to AGC}

Figure 2 shows the schematic of the two-area system with GCSC which is placed in series with the tie-line near to area-1. The tie-line active power can be easily extracted by:

$$
P_{12}=\frac{\left|V_{1}\right| \cdot\left|V_{2}\right|}{X_{12}-X_{G C S C}} \sin \delta_{12}
$$

where $X_{12}$ and $X_{G C S C}$ are the tie-line and GCSC reactance, respectively. Considering the series compensation ratio of $K_{C}=X_{G C S C} / X_{12}$, equation (1) can be rewritten as:

$$
P_{12}=\frac{\left|V_{1}\right| \cdot\left|V_{2}\right|}{\mathrm{X}_{12}\left(1-K_{C}\right)} \sin \delta_{12}
$$

Equation (2) can be separated into two terms as:

$$
P_{12}=\frac{\left|V_{1}\right| \cdot\left|V_{2}\right|}{X_{12}} \sin \delta_{12}+\frac{K_{C}}{1-K_{C}} \cdot \frac{\left|V_{1}\right| \cdot\left|V_{2}\right|}{X_{12}} \sin \delta_{12}
$$

In (3), the first term represents the power flow in the tie-line without GCSC and the second term defines the contribution of GCSC in the tie-line power flow. Under a slight change in values of $\delta_{1}, \delta_{2}, K_{C}$ from their nominal values $\delta_{1}^{0}, \delta_{2}^{0}, K_{C}^{0}$, the incremental tie-line power flow can be found by linearization of (3) around an operating point as: 


$$
\Delta P_{12}=\frac{\left|V_{1}\right| \cdot\left|V_{2}\right|}{X_{12}} \cos \delta_{12}^{0} \sin \Delta \delta_{12}+\frac{K_{C}}{\left(1-K_{C}^{0}\right)^{2}} \cdot \frac{\left|V_{1}\right| \cdot\left|V_{2}\right|}{X_{12}} \sin \delta_{12}^{0} \cdot \Delta K_{C}
$$

Also, under a slight perturbation in the load real power, the variation of voltage angles are practically very small. Hence, $\sin \Delta \delta_{12} \approx \Delta \delta_{12}$. Therefor,

$$
\begin{aligned}
& \Delta P_{12}=\frac{\left|V_{1}\right| \cdot\left|V_{2}\right|}{X_{12}} \cos \delta_{12}^{0} \Delta \delta_{12}+\frac{K_{C}}{\left(1-K_{C}\right)^{2}} \cdot \frac{\left|V_{1}\right| \cdot\left|V_{2}\right|}{X_{12}} \sin \delta_{12}^{0} \cdot \Delta K_{C} \\
& T_{12}=\frac{\left|V_{1}\right| \cdot\left|V_{2}\right|}{X_{12}} \cos \delta_{12}^{0} \quad ; C=\frac{1}{\left(1-K_{C}^{0}\right)^{2}} \cdot \frac{\left|V_{1}\right| \cdot\left|V_{2}\right|}{X_{12}} \sin \delta_{12}^{0}
\end{aligned}
$$

where $T_{12}$ and $C$ are the synchronizing coefficient and a constant value, respectively. So, (5) reduces to:

$$
\Delta P_{12}=T_{12} \Delta \delta_{12}+C \cdot \Delta K_{C}
$$

Also it can be noted that:

$$
\Delta \delta_{1}=2 \pi \int \Delta f_{1} d t \quad \text { and } \quad \Delta \delta_{2}=2 \pi \int \Delta f_{2} d t
$$

Therefore, Laplace transformation of (7) gives:

$$
\Delta P_{12}(\mathrm{~s})=\frac{2 \pi T_{12}}{s}\left[\Delta F_{1}(\mathrm{~s})-\Delta F_{2}(\mathrm{~s})\right]+C \cdot \Delta K_{C}(\mathrm{~s})
$$

Equation (9) can be rewritten as:

$$
\begin{aligned}
& \Delta P_{12}(\mathrm{~s})=\Delta P_{12}^{0}(\mathrm{~s})+\Delta P_{G C S C}(\mathrm{~s}) \\
& \Delta P_{G C S C}(\mathrm{~s})=C \cdot \Delta K_{C}(\mathrm{~s})
\end{aligned}
$$

where $\Delta P_{12}^{0}$ denotes the incremental tie-line power flow without the GCSC and $\triangle P_{G C S C}(\mathrm{~s})$ represents the effect of the GCSC in the tie-line power flow exchange. For realizing a sustainable GCSC-based damping controller, the constant of $C$ is included in the GCSC proportional gain. 
To obtain a high-performance GCSC-based damping controller, the PI controller is included. Therefore, $\Delta P_{G C S C}(\mathrm{~s})$ can be rewritten as follows:

$$
\begin{aligned}
& \Delta P_{G C S C}(\mathrm{~s})=P I . \Delta E_{\text {error }}(\mathrm{s}) \\
& P I=K_{P}+\frac{K_{I}}{s}
\end{aligned}
$$

where $K_{P}$ and $K_{I}$ indicate the adjustable proportional and integral gain values in the structure of the GCSC-based damping PI controller, respectively. As can be seen from Fig. 1, the GCSCbased controller receives the frequency deviation of area $1\left(\Delta f_{1}\right)$ as the control signal. Therefore, it can be inferred that:

$$
\Delta E_{\text {error }}(\mathrm{s})=\Delta f_{1}(s)
$$

Nowadays, the application of nature-inspired intelligent methods have been accomplished for solving various optimization problems. In order to achieve high efficiency of the proposed controllers in AGC and GCSC from the point of view of improving the dynamic characteristics and oscillation damping, choosing the effective techniques for optimizing the parameters of controllers is very important. In this paper, at first, the gain values of PI controller in the GCSC structure and the integral controller in AGC loop are tuned by optimization algorithms known as SCA, ABC, IPSO, GA, and ACO. In this regard, selection of appropriate objective function is necessary for fine tuning of parameters by optimization algorithms.

\section{Objective Function Formulation}

For the sake of nature-inspired and heuristic optimization techniques application, definition of an appropriate objective function is essential. The objective function should be defined so that the output characteristics in the time domain such as peak overshoot, settling time and peak time of the considered variables are minimized. In the present work, the integral of time multiplied squared error (ITSE) performance index is regarded as the objective function in order to damp 
the tie-line power and frequency oscillations effectively. It has been reported in many studies that the ITSE index in comparison with the other performance indices such as the integral of squared error (ISE), integral of absolute error (IAE) and the integral of time multiplied absolute error (ITAE) demonstrates the quality of system performance effectively. Five optimization techniques known as SCA, ABC, IPSO, GA, and ACO are employed here to minimize the ITSE index and satisfy the gains of integral controller $\left(K_{I 1}, K_{I 2}\right)$ in AGC loop and PI controller $\left(K_{I_{G C S C}}, K_{P_{G C S C}}\right)$ in GCSC structure, subjected to some constraints. To better understanding of the optimization process, the objective function, decision variables and constraints are denoted as the following:

Objective Function:

$$
\text { Min ITSE }=\int_{0}^{T_{\text {sim }}} t\left[\Delta f_{1}^{2}+\Delta f_{2}^{2}+\Delta P_{\text {tie }}^{2}\right] d t
$$

Decision variables:

$$
K_{I 1}, K_{I 2}, K_{I_{G C S C}}, K_{P_{G C S C}}
$$

Constraints:

$$
\begin{gathered}
K_{I_{\min }} \leq K_{I 1}, K_{I 2}, K_{I_{G C S C}} \leq K_{I_{\max }} \\
K_{P_{\min }} \leq K_{P_{G C S C}} \leq K_{P_{\max }}
\end{gathered}
$$

where $T_{\text {sim }}$ denotes the final simulation time in seconds. $\Delta f_{1}$ and are the frequency $\Delta f_{2}$ deviations of area-1 and area-2, respectively. $\Delta P_{\text {tie }}$ is the tie-line power change. As it is common in optimization algorithms, the upper and lower limits of each parameters in equation (17) are selected by the knowledge of designer based on his/her experience about FACTS devices and their performance in LFC. All of the optimization algorithms are coded as .m files and linked with the SIMULINK environment of MATLAB software to obtain the gains of the controllers through minimizing the ITSE index.

\section{Employed Heuristic Optimization Algorithms}


To select the most efficient optimization algorithm to optimize the fuzzy controller, a range of heuristic optimization algorithms consist of SCA, ABC, IPSO, GA, and ACO are examined in this research for the LFC structure. GA, ACO, and PSO are effective and efficient heuristic algorithms that have been widely applied with success to many real-world problem and thus appear a natural choice for being adopted like benchmark algorithms. The superiority of the SCA algorithm over other heuristic techniques (PSO, GA etc.) has been shown in [32] and it has successfully applied in LFC studies [7, 33].

\subsection{Sine cosine algorithm}

Sine cosine algorithm (SCA), developed by Mirjalili [32] in 2016, is a new population-based optimization method for solving optimization problems. The optimization process in SCA is based-on a set of random solutions that applies a sine and cosine functions based-on mathematical model to fluctuate outwards or towards the best solution. The SCA has two phases named as exploration and exploitation in the optimization process. To establish exploration and exploitation of the search space to rapid achievement of the optimal solution, this algorithm uses many random and adaptive variables. The position updating equation related to any search agent $X_{i}$ can be written as follows:

$$
\begin{aligned}
& X_{i}^{t+1}= \begin{cases}X_{i}^{t}+r_{1} \times \sin \left(\mathrm{r}_{2}\right) \times\left|r_{3} P_{i}^{t}-X_{i}^{t}\right| & r_{4}<0.5 \\
X_{i}^{t}+r_{1} \times \cos \left(\mathrm{r}_{2}\right) \times\left|r_{3} P_{i}^{t}-X_{i}^{t}\right| & r_{4} \geq 0.5\end{cases} \\
& r_{1}=c-t \frac{c}{T}
\end{aligned}
$$

where $X_{i}^{t}$ and $P_{i}^{t}$ are the position of the current solution and the position of the best solution in $j^{\text {th }}$ dimension at $t^{\text {th }}$ iteration, respectively. $r_{1}, r_{2}, r_{3}$ and $r_{4}$ are random numbers. $r_{1}$ is a control parameter that states the next position which could be either in the space between the solution and destination or outside. In (17), $t$ is the current iteration, $T$ is the maximum number of 
iterations, and $c$ is a constant. The superiority of the SCA algorithm over other heuristic techniques (PSO, GA etc.) has been shown in [32]. In this research, the adjustable parameters of this algorithm are considered as follows: number of iterations $=50$, number of search agents $=10$ and $\mathrm{c}=2$.

\subsection{Artificial bee colony algorithm}

$\mathrm{ABC}$ is one of the more recent population-based optimization methods. This algorithm tries to solve the optimization problems by simulating the searching behavior of honey bees for foraging; and it belongs to the group of nature-inspired intelligent algorithms that was proposed by $[34,35]$. In this algorithm, the colony of artificial bees consists of three groups of bees: employed bees, onlooker bees, and scout bees. Each bee has a food source in its memory and searches food around this location. In this regard, the $\mathrm{ABC}$ generates an initial randomly solutions (food sources), which are equal to the swarm size of $S N$ as follows:

$$
X_{i}=X_{i}^{\min }+\operatorname{rand}(0,1) \times\left(X_{i}^{\max }-X_{i}^{\min }\right) \quad \forall i=1,2, \ldots, S N
$$

where $X_{i}=\left(x_{i, 1}, x_{i, 2}, \ldots, x_{i, \mathrm{n}}\right)$ states each solution of $i^{\text {th }}$ solution. $n$ is the dimension size of solution. For the implementation of a new candidate solution from the previous one, the $\mathrm{ABC}$ applies the following equation:

$$
V_{i, j}=X_{i, j}+\Phi_{i, j} \times\left(X_{i, j}-X_{\mathrm{k}, j}\right)
$$

where $K \in\{1,2, \ldots, S N\}$ is a random dimension index and $\Phi_{i, j}$ is a random number within [-1, 1]. Afterward, an onlooker bee evaluates the nectar information and chooses a solution (food source) with a probability related to its nectar amount, which is given by the following equation:

$$
P_{i}=\frac{f i t_{i}}{\sum_{i=1}^{S N} f i t_{i}}
$$


where $f i t_{i}$ is the fitness value of the $i^{t h}$ solution. The better solution is selected based-on higher probability. Finally, this process continues until convergence criteria will be achieved. In this research, the adjustable important parameters of this algorithm are chosen as: number of iteration $=50, S N=10$.

\subsection{Improved particle swarm optimization algorithm}

PSO algorithm is an optimization method in the group of heuristic computational algorithms which is inspired by the sociological behavior of birds flocking [36]. This algorithm uses a number of particles to move around the search space to find the best solutions for optimization problems. For the case that there is large diversity in populations, an improved PSO (IPSO) algorithm recently has been used in [9] for FACTS in LFC, which employs crossover operator so that the search space can be successfully surveyed. In this research, the adjustable important parameters of this algorithm are chosen as: number of iteration $=50$, size of particles $=30$, $c_{1}=c_{2}=2$, initial weights $=0.9$, final weights $=0.4$, and crossover rate $=0.6$.

\subsection{Genetic algorithm}

Genetic algorithm (GA) is a heuristic optimization method for solving optimization problems by exploitation of a random search that was first proposed by John Holland [36]. This algorithm applies the natural selection and genetic mechanisms and imitates the process of natural systems necessary evolution based-on a population of candidate solutions. A new generation is created by applying the three following operators to the current population: reproduction, crossover and mutation which more details about this algorithm can be found in [37]. Finally, the optimization process by GA continues until running out the maximum iteration. In this research, the adjustable parameters of GA are chosen as: number of iteration $=50$, number of population $=20$ and mutation rate $=0.2$.

\subsection{Ant colony optimization algorithm}


Introduced by M. Dorigo [38], ant colony optimization (ACO) approach is a nature inspired swarm intelligence method for solving the optimization problems. ACO has been successfully applied in a wide range of science for optimization (see e.g., $[39,40]$ ). This algorithm is based on the real ant behavior in seeking food source. In ACO, the basic rule is that shortest path has large pheromone concentrations, so that more ants tend to choose it to travel. The global updating rule is implemented in the ant system where all ants start their tours and pheromone is updated based on:

$$
\tau_{i j}(t+1)=(1-\rho) \tau_{i j}(t)+\sum_{k} \frac{Q}{L_{k}}
$$

where $\rho$ is the evaporation rate, $\tau_{i j}$ is the probability between the town $i$ and $j, Q$ is constant, $L_{k}$ is the length of the tour performed by $K$ th ant. In this research, the adjustable parameters of ACO are chosen as: number of iteration $=50$, number of ants $=20$, pheromone $=0.6$, and evaporation rate $=0.95$.

\subsection{Convergence trend of the applied algorithms}

Figure 3 shows the convergence trend of employed optimization algorithms in LFC issue of the concerned power system. It is clearly evident from this figure that SCA converges to the optimal solution faster and gives the better global optimal solution over ABC, PSO, ACO and GA algorithms before it reached the maximum iteration. As obvious, the SCA is the most powerful algorithm among the others in the case of FACTS in LFC structure. Therefore, in the next section the fuzzy controller is optimized by SCA for efficient frequency control.
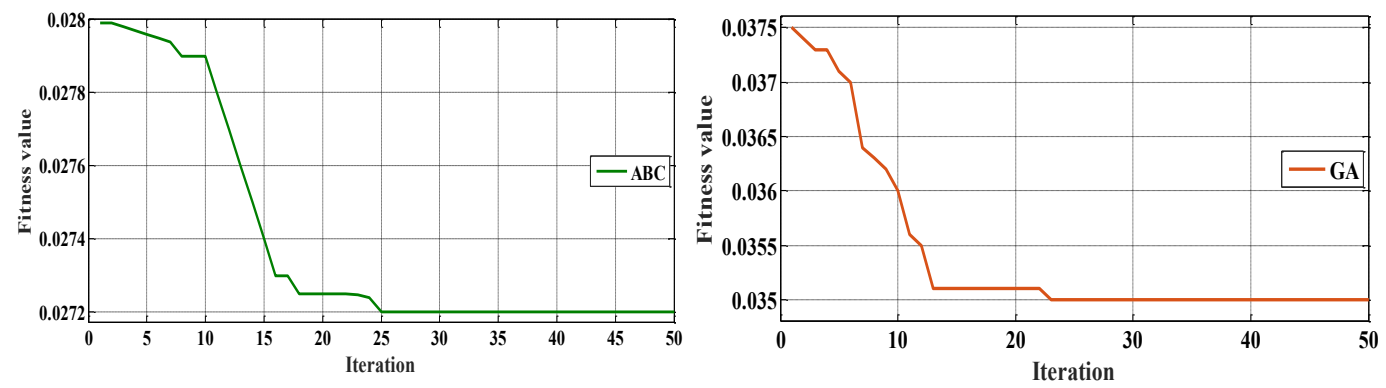

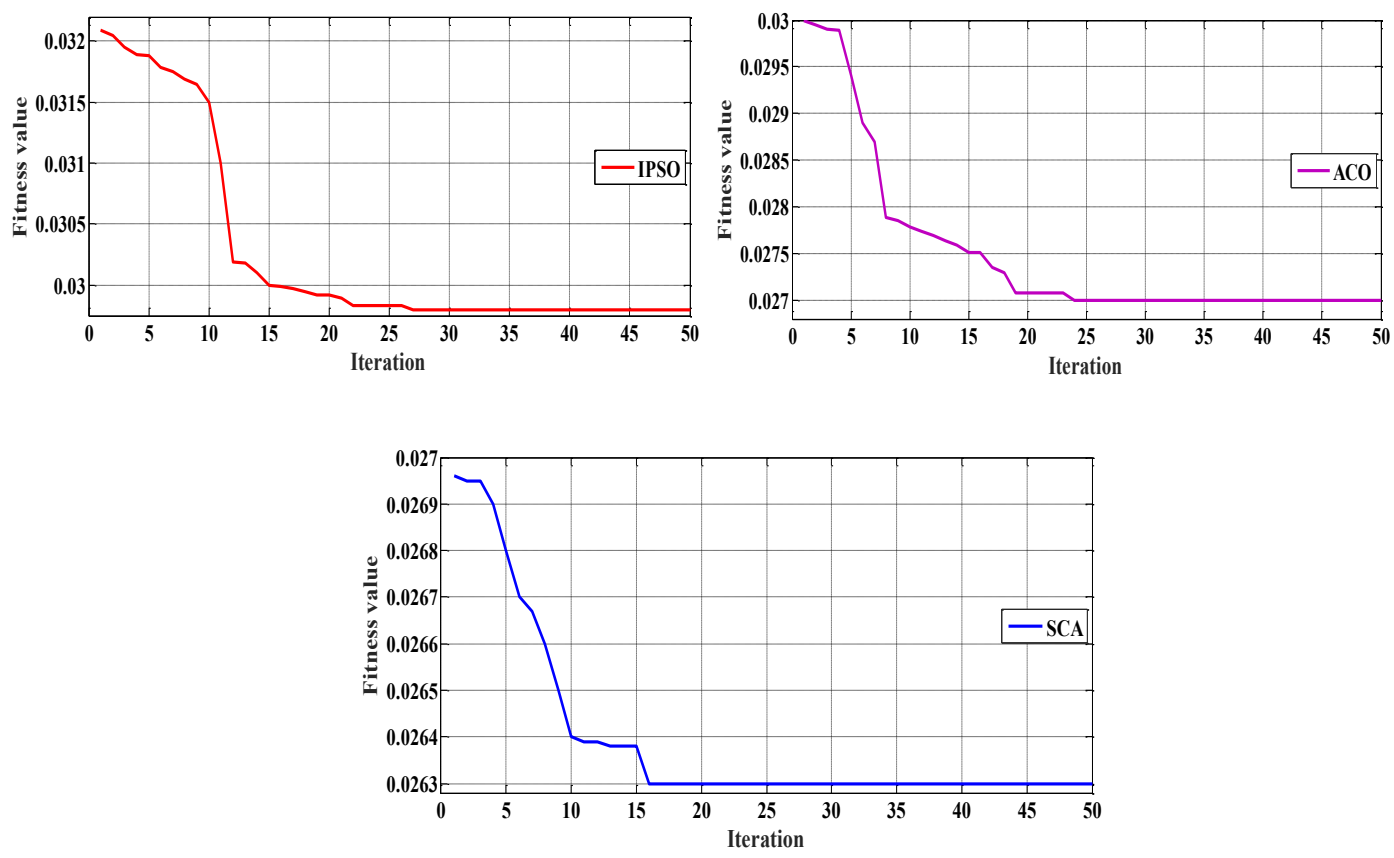

Fig. 3. Convergence characteristics of the proposed optimization algorithms

\section{Design of Optimized Fuzzy Fine-Tuning Controller}

Frequency regulation of power systems based on fuzzy logic method has attracted much attention [41-43]. Designing a fuzzy logic controller includes four sections: fuzzification, fuzzy rule base, inference engine, and defuzzification. The first section, known as fuzzification, converts the crisp data to a linguistic variable using the membership functions. The responsibility of defuzzification section is vice versa. The fuzzy rule base section represents the information storage for linguistic variables as the database. A lookup table is appointed to define the controller output for all possible combinations of input signals. In this regard, the fuzz system is characterized by a set of linguistic statements in form of "IF-THEN" rules. Also, the inference engine uses the established "IF-THEN" rules to convert the fuzzy input into the fuzzy output.

The designed fuzzy controller in this paper has two inputs and one output. The area control error (ACE) and its derivative have been selected as input signals and the output signal has been distributed to proportional and integral gains in GCSC controller and the integral gain in AGC of the second area. Generally, integral controllers are employed in AGC structure of power systems. 
Since the GCSC receives the frequency deviation from the first area, only the second area has been selected to support by the fuzzy controller. The ACE signal can be mathematically represented as follows:

$$
A C E=\Delta P_{t i e}+\beta . \Delta f
$$

where, $\beta, \Delta P_{\text {tie }}$ and $\Delta f$ are the area bias factor, tie-line power and frequency deviation.

In the design process, triangular formed membership functions have been selected in the interval of $[-1,1]$. The membership functions are demonstrated in Fig. 4 for inputs and output. As seen, the membership functions corresponding to the inputs are arranged as negative $(\mathrm{N})$, zero $(\mathrm{Z})$, and positive $(\mathrm{P})$; the membership functions for the output variable is arranged as negative large (NL), negative small (NS), zero (Z), positive small (PS), and positive large (PL). Table 1 presents the rules of the designed fuzzy controller.

Table 1. Fuzzy rules for the controller

\begin{tabular}{|c|c|c|c|c|}
\cline { 2 - 5 } \multicolumn{2}{c|}{} & \multicolumn{3}{|c|}{$d \Delta P_{\text {tie }} / d t$} \\
\cline { 2 - 5 } \multicolumn{2}{c|}{$\Delta P_{t i e}$} & $\mathbf{N}$ & $\mathbf{Z R}$ & $\mathbf{P}$ \\
\cline { 2 - 5 } & $\mathbf{Z R}$ & $\mathbf{P B}$ & $\mathbf{P S}$ & $\mathbf{P S}$ \\
\cline { 2 - 5 } & $\mathbf{P}$ & $\mathbf{Z R}$ & $\mathbf{N S}$ \\
\hline
\end{tabular}
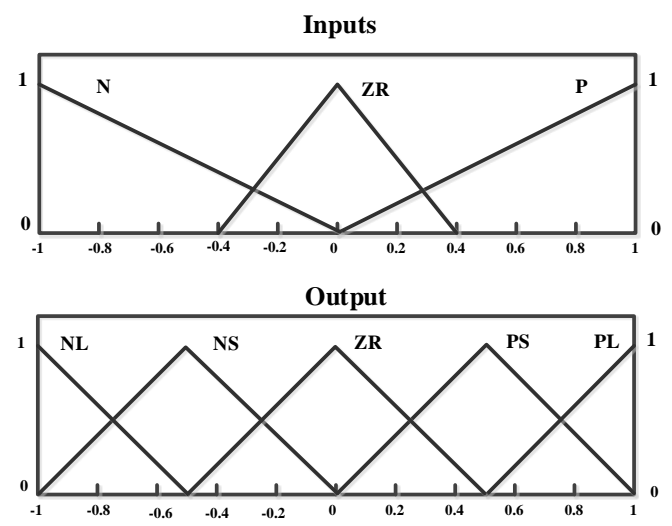
Fig. 4. Membership functions of fuzzy controller for inputs and output

To normalize and adopt the input and output signals for the controller, some scaling factors have been added before the inputs and after the output signal. The values of these scaling factors have been optimized using SCA (which its superiority was shown in previous section) and by minimizing the fitness function. The main structure of fuzzy controller after addition of scaling factors has been shown in Fig. 5. By combination between the optimization algorithm and fuzzy logic, the obtained controller can be called as optimized fuzzy fine-tuning (OFFT) controller. To describe why fuzzy coordinator or OFFT controller is used in this research, it should be noted that the proposed algorithms optimize the gains of classic controllers in an offline manner. This means that the controllers have constant gains during all of the conditions. However, adapting the controller gains during disturbances in an online manner is a wisely strategy. Therefore, the fuzzy coordinator generates online supplementary gains for the classic controllers in the power system.

The objective function in this stage is same as the previous objective function (ITSE). Also, $\alpha_{1}, \alpha_{2}, \beta_{1}, \beta_{2}$, and $\beta_{3}$ are the decision variables which the constraints over them are defined as follows:

$$
\begin{aligned}
& \alpha_{\text {min }} \leq \alpha_{1}, \alpha_{2} \leq \alpha_{\text {max }} \\
& \beta_{\text {min }} \leq \beta_{1}, \beta_{2}, \beta_{3} \leq \beta_{\text {max }}
\end{aligned}
$$




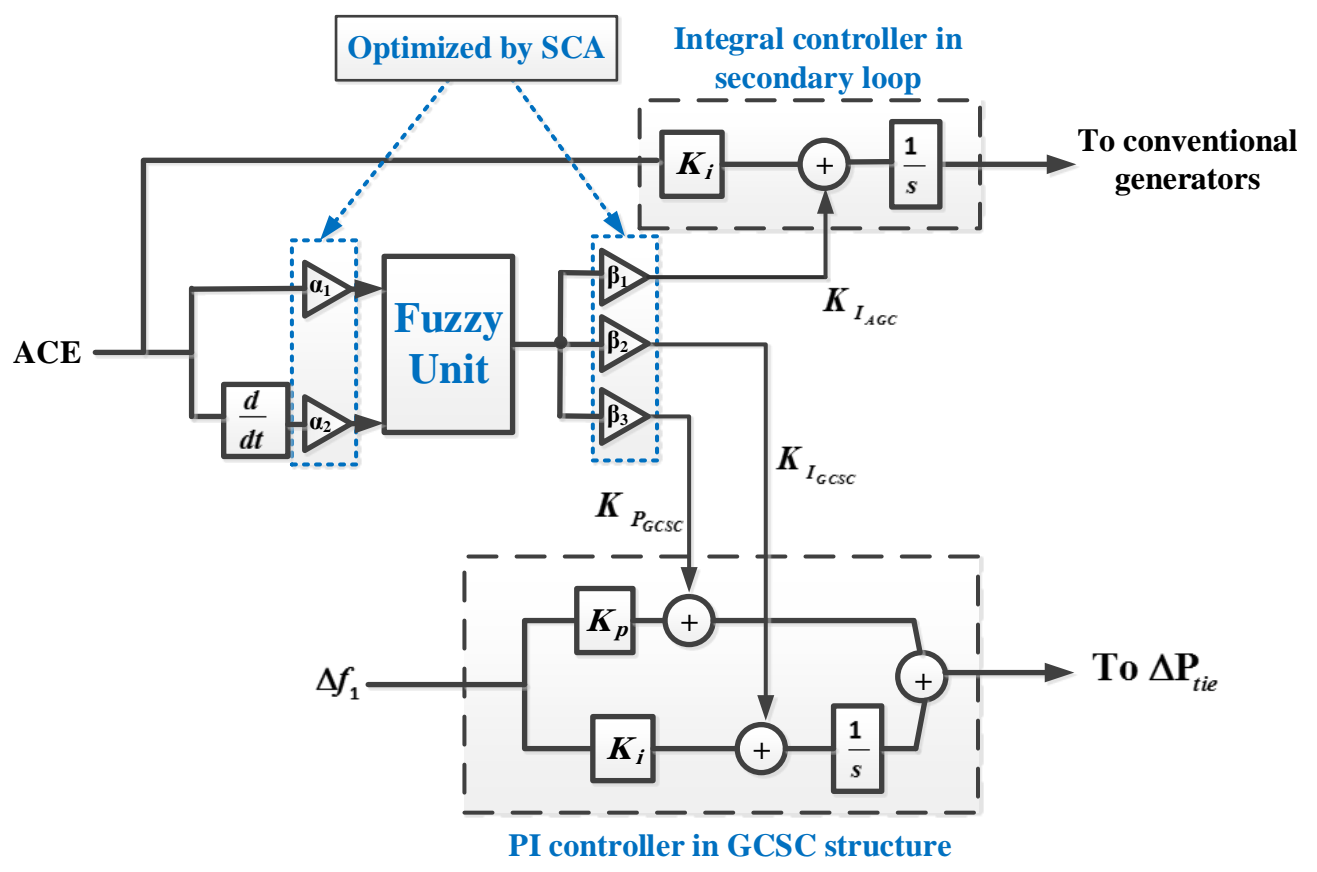

Fig. 5. Proposed control framework for OFFT approach

\section{Numerical Studies and Discussion}

To validate the performance of the proposed OFFT-based LFC, two scenarios are devised and put under extensive simulation studies in MATLAB/Simulink software. The understudy system as a two-area hybrid power system and the GCSC model for LFC problems were explained in second section. Due to concerns about the impacts of series FACTS on subsynchronous resonance, Mohammadpour et al. [44] has shown that the GCSC can be used to mitigate the sub-synchronous resonance effectively in wind farms. Also, it is shown in [45] that appropriate control strategy for GCSC can improve both the sub-synchronous resonance and low frequency oscillations in power systems.

As discussed earlier, the performance of the OFFT controller is compared with several optimization algorithms. The obtained gains of the existence controllers in the system by these optimization algorithms are exhibited in Table 2. This is while, the OFFT tries to change the gains online and dynamically in disturbances. The obtained scale factors for the OFFT controller through SCA algorithm are $\alpha_{1}=0.32, \alpha_{2}=3, \beta_{1}=0.16, \beta_{2}=0.3$, and $\beta_{3}=0.35$. The 
outperformance of the proposed OFFT is demonstrated in three scenarios including step and random load perturbations, and sensitivity analysis against $\pm 25 \%$ deviation in synchronizing coefficient.

Table 2. Optimal parameters of controllers obtained by SCA, ACO, ABC, GA and IPSO algorithms

\begin{tabular}{|c|c|c|c|c|c|}
\hline $\begin{array}{l}\text { Optimization } \\
\text { techniques }\end{array}$ & $K_{I 1}$ & $K_{I 2}$ & $K_{P_{G C S C}}$ & $K_{I_{G C S C}}$ & ITSE \\
\hline \multirow{4}{*}{$S C A$} & 0.1274 & 0.1598 & 0.1009 & 0.0250 & \multirow{4}{*}{0.0263} \\
\hline & 0.1232 & 0.1542 & 0.1023 & 0.0222 & \\
\hline & 0.1284 & 0.1588 & 0.1042 & 0.0189 & \\
\hline & 0.1255 & 0.1580 & 0.1011 & 0.0202 & \\
\hline \multirow{4}{*}{$A C O$} & 0.1398 & 0.1612 & 0.1020 & 0.0450 & \multirow{4}{*}{0.0270} \\
\hline & 0.1434 & 0.1701 & 0.0987 & 0.0441 & \\
\hline & 0.1412 & 0.1629 & 0.1106 & 0.0401 & \\
\hline & 0.1511 & 0.1688 & 0.1025 & 0.0479 & \\
\hline \multirow{4}{*}{$A B C$} & 0.1333 & 0.1666 & 0.0712 & 0.0119 & \multirow{4}{*}{0.0272} \\
\hline & 0.1379 & 0.1627 & 0.0834 & 0.0083 & \\
\hline & 0.1402 & 0.1627 & 0.0853 & 0.0143 & \\
\hline & 0.1322 & 0.1650 & 0.0857 & 0.0156 & \\
\hline \multirow{4}{*}{ IPSO } & 0.1539 & 0.1695 & 0.0450 & 0.0118 & \multirow{4}{*}{0.0298} \\
\hline & 0.1466 & 0.1611 & 0.0440 & 0.0184 & \\
\hline & 0.1581 & 0.1721 & 0.0419 & 0.0116 & \\
\hline & 0.1509 & 0.1677 & 0.0501 & 0.0134 & \\
\hline \multirow{4}{*}{$G A$} & 0.1474 & 0.1693 & 0.0244 & 0.0141 & \multirow{4}{*}{0.0350} \\
\hline & 0.1491 & 0.1699 & 0.0311 & 0.0155 & \\
\hline & 0.1467 & 0.1707 & 0.0288 & 0.0153 & \\
\hline & 0.1500 & 0.1699 & 0.0276 & 0.0139 & \\
\hline
\end{tabular}

\subsection{First scenario: Step load perturbation}

As the first scenario, a 0.01 p.u. step load change has applied to the first area in the system. The frequency and tie-line power deviations are demonstrated in Fig. 6 after this disturbance. As 
it is obvious, the OFFT controller has less peak overshoot, better settling time and oscillation damping compared with the optimization algorithms.
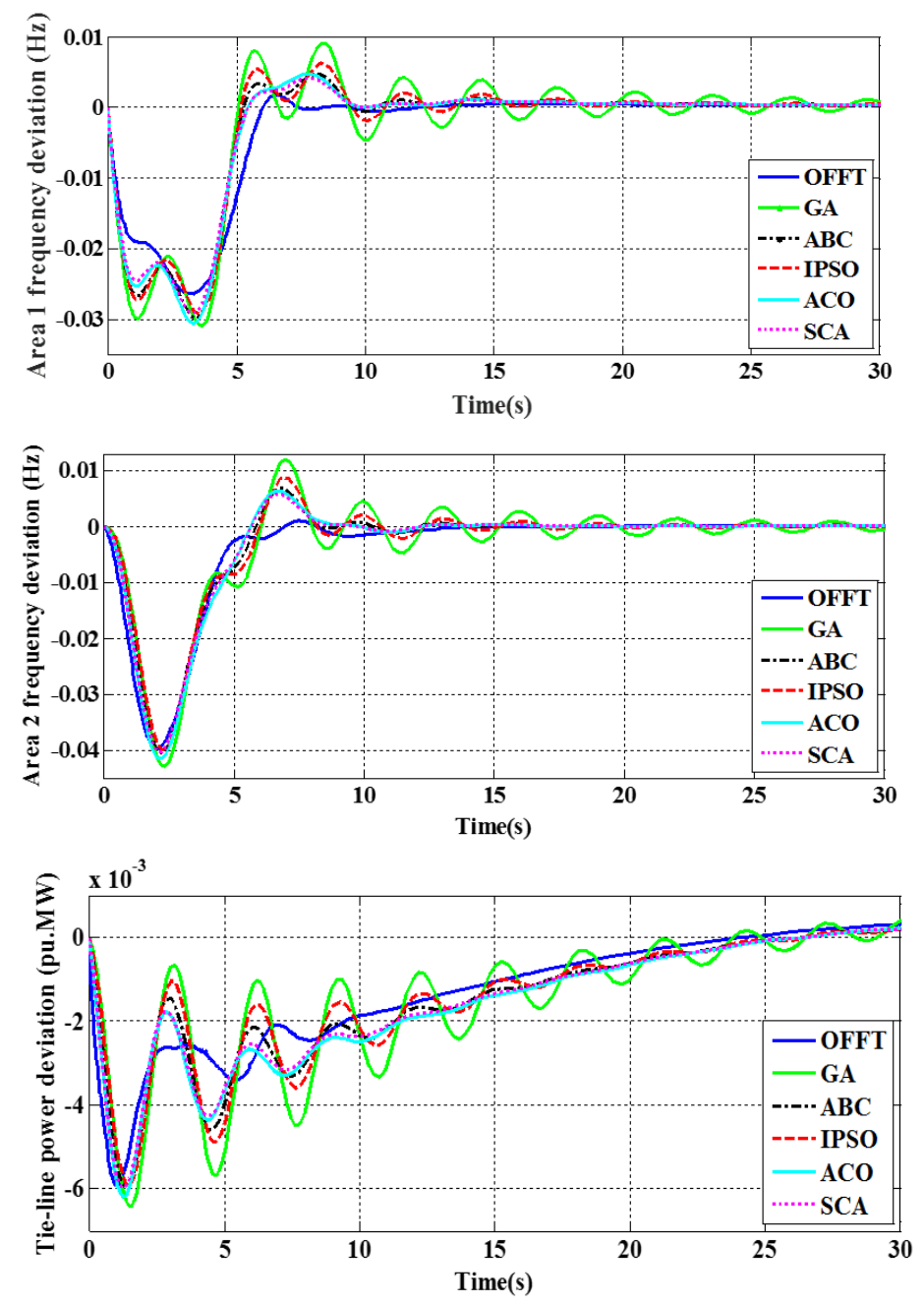

Fig. 6. Frequency and tie-line power deviations after SLP

Also, the effectiveness of the OFFT controllers is verified through various indices such as the integral of absolute value of the error (IAE), the integral of square error (ISE) and the integral of time multiply square absolute error (ITAE) are being utilized as:

$$
\begin{gathered}
I A E=\int_{0}^{T_{\text {sim }}} t\left[\left|\Delta f_{1}\right|+\left|\Delta f_{2}\right|+\left|\Delta P_{\text {tie }}\right|\right] d t \\
I S E=\int_{0}^{T_{\text {sim }}}\left[\Delta f_{1}^{2}+\Delta f_{2}^{2}+\Delta P_{\text {tie }}^{2}\right] d t \\
I T A E=\int_{0}^{T_{\text {sim }}} t\left[\left|\Delta f_{1}\right|+\left|\Delta f_{2}\right|+\left|\Delta P_{\text {tie }}\right|\right] d t
\end{gathered}
$$


Table 3 has denoted the values of damping ratio (DR), peak overshoot (PO), peak time (PT(s)), settling time (ST(s)), IAE, ISE and ITAE for all the employed controllers. As it can be seen, the proposed OFFT has better performance over the optimization algorithms in all of the considered indices. As well, the generated gains by OFFT which is added to the constant gains of GCSC and AGC controllers are illustrated in Fig. 7. The OFFT generates the supplementary gains in online manner and dynamically after disturbance and after mitigation of frequency, the generated gain reaches to zero; this is because of that, in steady state condition, the PI controller with constant gains can better support the system.

Table 3. Frequency deviation and tie-line power characteristics

\begin{tabular}{|c|c|c|c|c|c|c|c|c|}
\hline $\begin{array}{l}\text { Optimization } \\
\text { techniques }\end{array}$ & Signal & $D R$ & $P O$ & $P T(s)$ & $S T(s)$ & $I T A E$ & $I A E$ & $I S E$ \\
\hline \multirow{3}{*}{ OFFT } & $\Delta f_{1}$ & 0.0264 & 1.6439 & 3.2138 & 16.9748 & \multirow{3}{*}{1.1375} & \multirow{3}{*}{0.3386} & \multirow{3}{*}{0.0095} \\
\hline & $\Delta f_{2}$ & 0.0397 & 2.9679 & 2.0187 & 8.1224 & & & \\
\hline & $\Delta P_{12}$ & 0.0059 & -0.3855 & 1.0284 & 16.7357 & & & \\
\hline \multirow{3}{*}{$S C A$} & $\Delta f_{1}$ & 0.0292 & 1.9158 & 3.2920 & 17.0155 & \multirow{3}{*}{1.1592} & \multirow{3}{*}{0.3406} & \multirow{3}{*}{0.0101} \\
\hline & $\Delta f_{2}$ & 0.0403 & 3.0348 & 2.1124 & 8.2631 & & & \\
\hline & $\Delta P_{12}$ & 0.0060 & -0.3998 & 1.2649 & 18.9021 & & & \\
\hline \multirow{3}{*}{$A C O$} & $\Delta f_{1}$ & 0.0287 & 1.8709 & 3.3200 & 17.1993 & \multirow{3}{*}{1.1696} & \multirow{3}{*}{0.3431} & \multirow{3}{*}{0.0104} \\
\hline & $\Delta f_{2}$ & 0.0416 & 3.1539 & 2.1132 & 11.2789 & & & \\
\hline & $\Delta P_{12}$ & 0.0062 & -0.3815 & 1.2788 & 19.0486 & & & \\
\hline \multirow{3}{*}{$A B C$} & $\Delta f_{1}$ & 0.0299 & 1.9894 & 3.4303 & 17.7070 & \multirow{3}{*}{1.1697} & \multirow{3}{*}{0.3434} & \multirow{3}{*}{0.0104} \\
\hline & $\Delta f_{2}$ & 0.0405 & 3.0465 & 2.2585 & 11.4141 & & & \\
\hline & $\Delta P_{12}$ & 0.0060 & -0.4001 & 1.3779 & 18.8684 & & & \\
\hline \multirow{3}{*}{ IPSO } & $\Delta f_{1}$ & 0.0301 & 2.0100 & 3.5446 & 20.5401 & \multirow{3}{*}{1.2101} & \multirow{3}{*}{0.3491} & \multirow{3}{*}{0.0108} \\
\hline & $\Delta f_{2}$ & 0.0388 & 2.8789 & 2.2792 & 16.1890 & & & \\
\hline & $\Delta P_{12}$ & 0.0058 & -0.4240 & 1.4849 & 17.7754 & & & \\
\hline \multirow{3}{*}{$G A$} & $\Delta f_{1}$ & 0.0310 & 2.0998 & 3.5692 & 30.0000 & \multirow{3}{*}{1.2870} & \multirow{3}{*}{0.3580} & \multirow{3}{*}{0.0116} \\
\hline & $\Delta f_{2}$ & 0.0429 & 3.2892 & 2.3668 & 28.4537 & & & \\
\hline & $\Delta P_{12}$ & 0.0064 & -0.3588 & 1.5623 & 20.2007 & & & \\
\hline
\end{tabular}



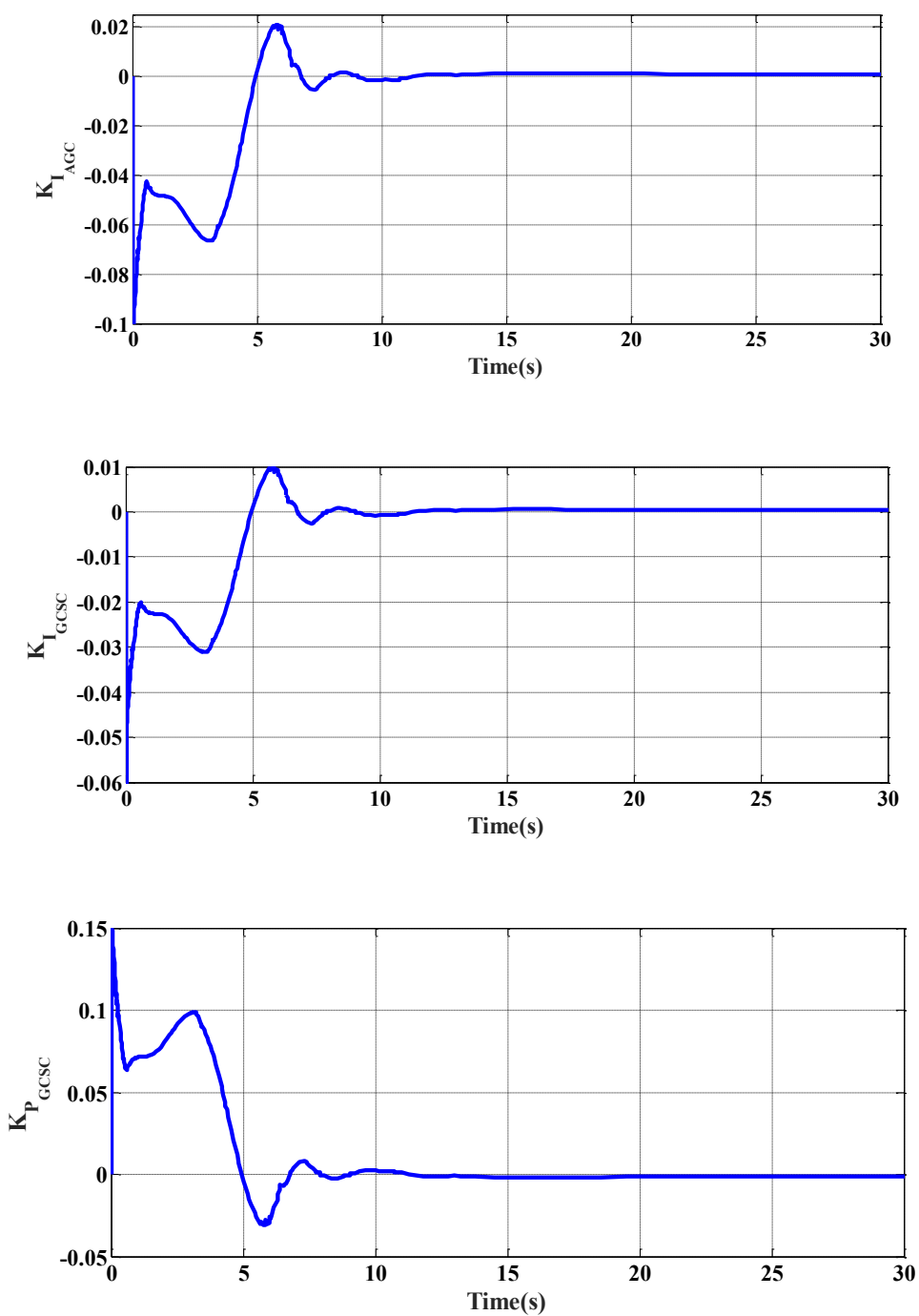

Fig. 7. The generated signals for GCSC and AGC from OFFT after SLP

\subsection{Second scenario: Random load perturbation}

To have more realistic scenario, a random load perturbation (RLP) has been selected to verify the performance of the OFFT controller. In real power systems, load of system may change several times during a time period. In this paper, the RLP has been organized as demonstrated in Fig. 8. According to this figure, the load is changed in five steps. 


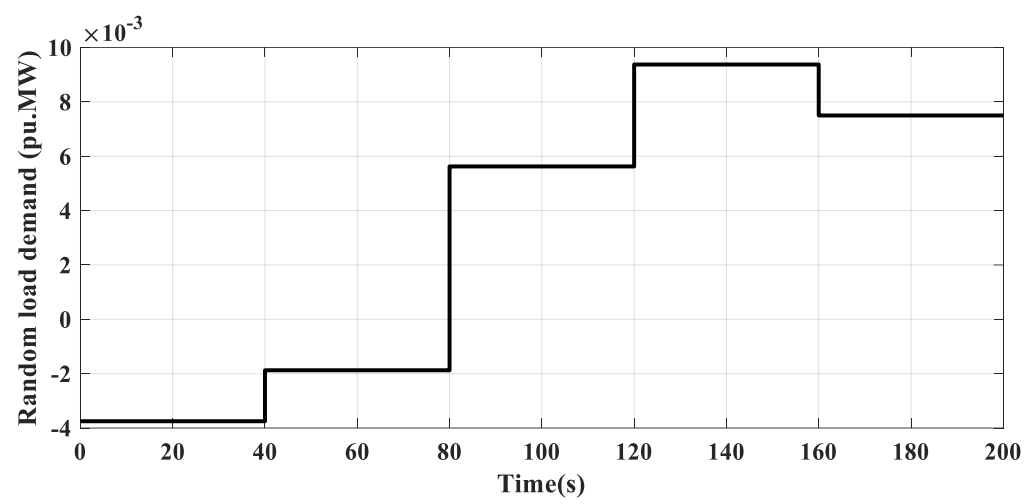

Fig. 8. The RLP scenario

Figure 9 demonstrates the frequency and tie-line power deviation after the RLP scenario. The performance of OFFT controller is obvious in this figure. To be more accurate, the frequency and power performance are exhibited with more zoom in the figure. Again, the OFFT controller has lesser overshoots, better settling time and oscillation damping compared to the optimization algorithms. Also, with the aim of a better performance evaluation of the OFFT controller, the online trend of gain tuning in LFC is depicted in Fig. 10. Contemplating this figure, the adaptive performance of the OFFT approach is recognized easily. As can be seen in these figures, when the load changed, the gains change rapidly.

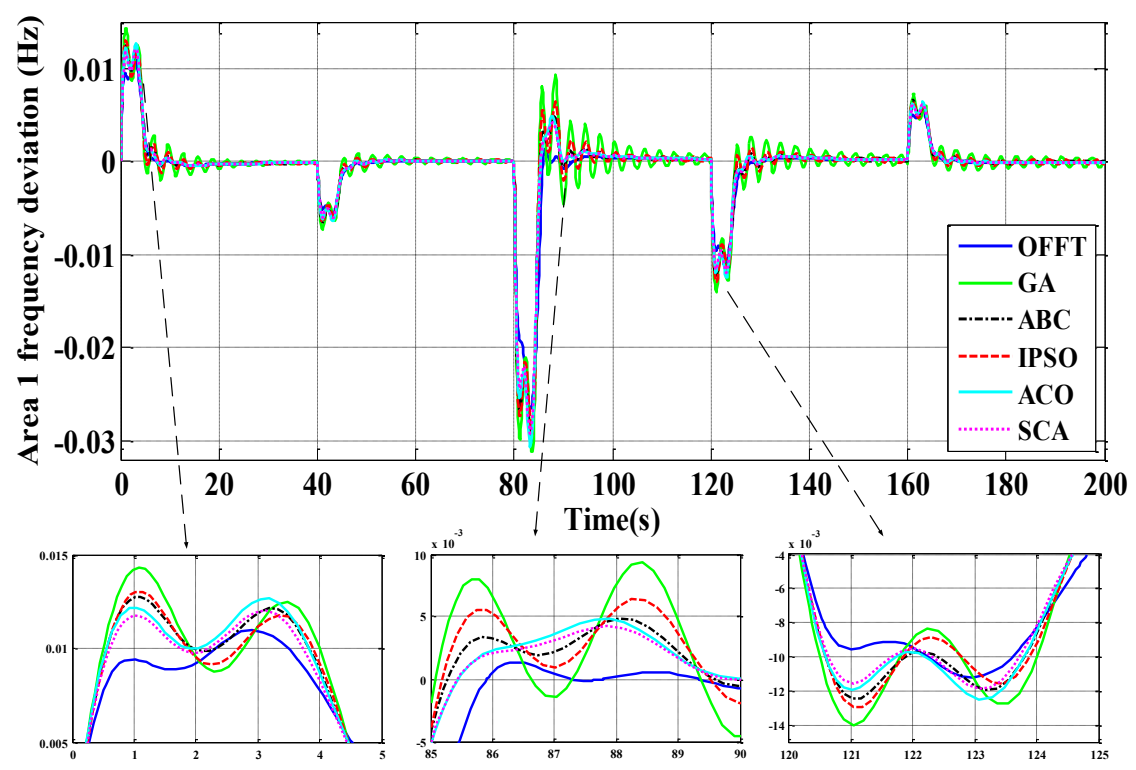



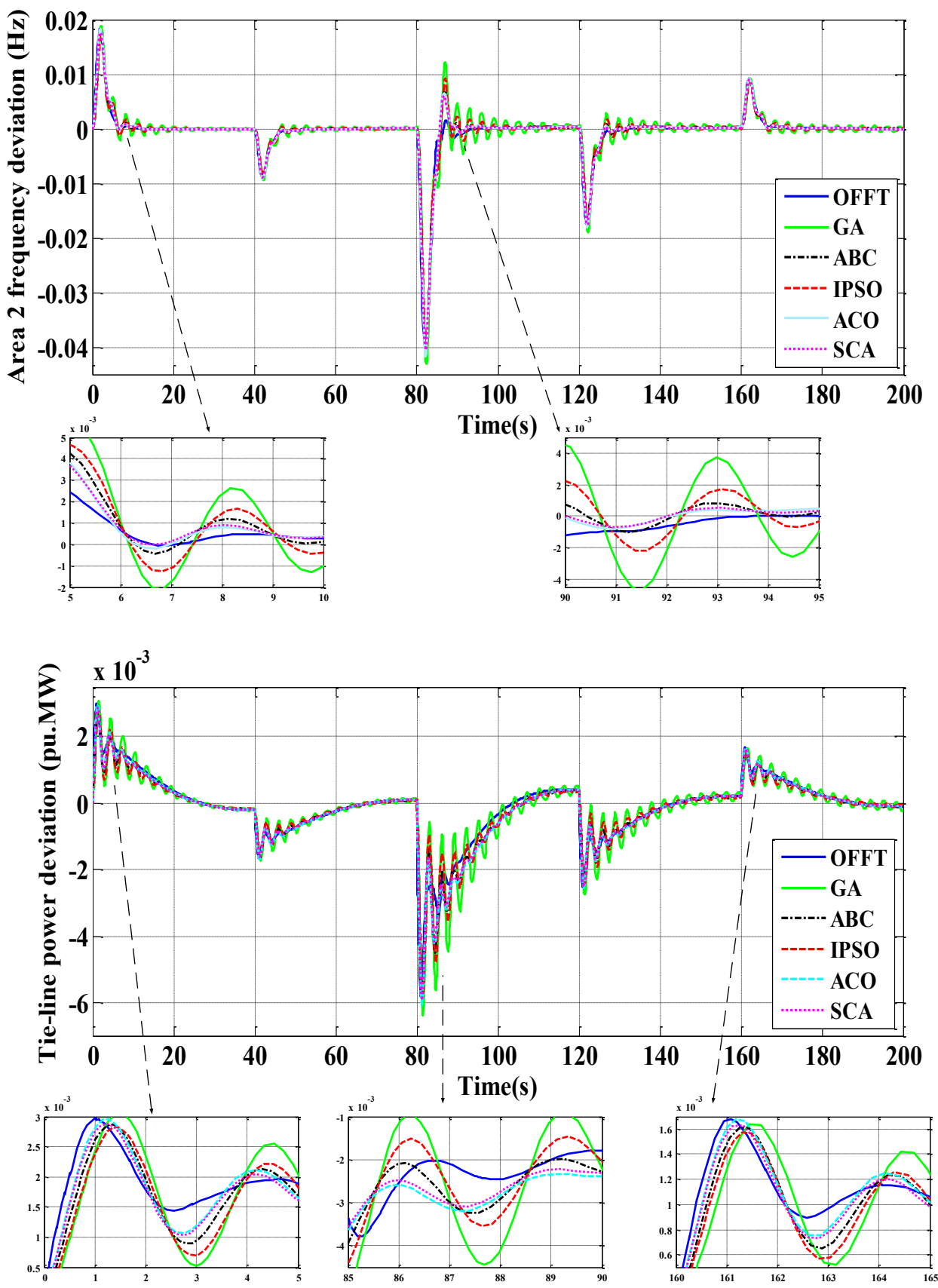

Fig. 9. Frequency and tie-line power deviations after RLP 

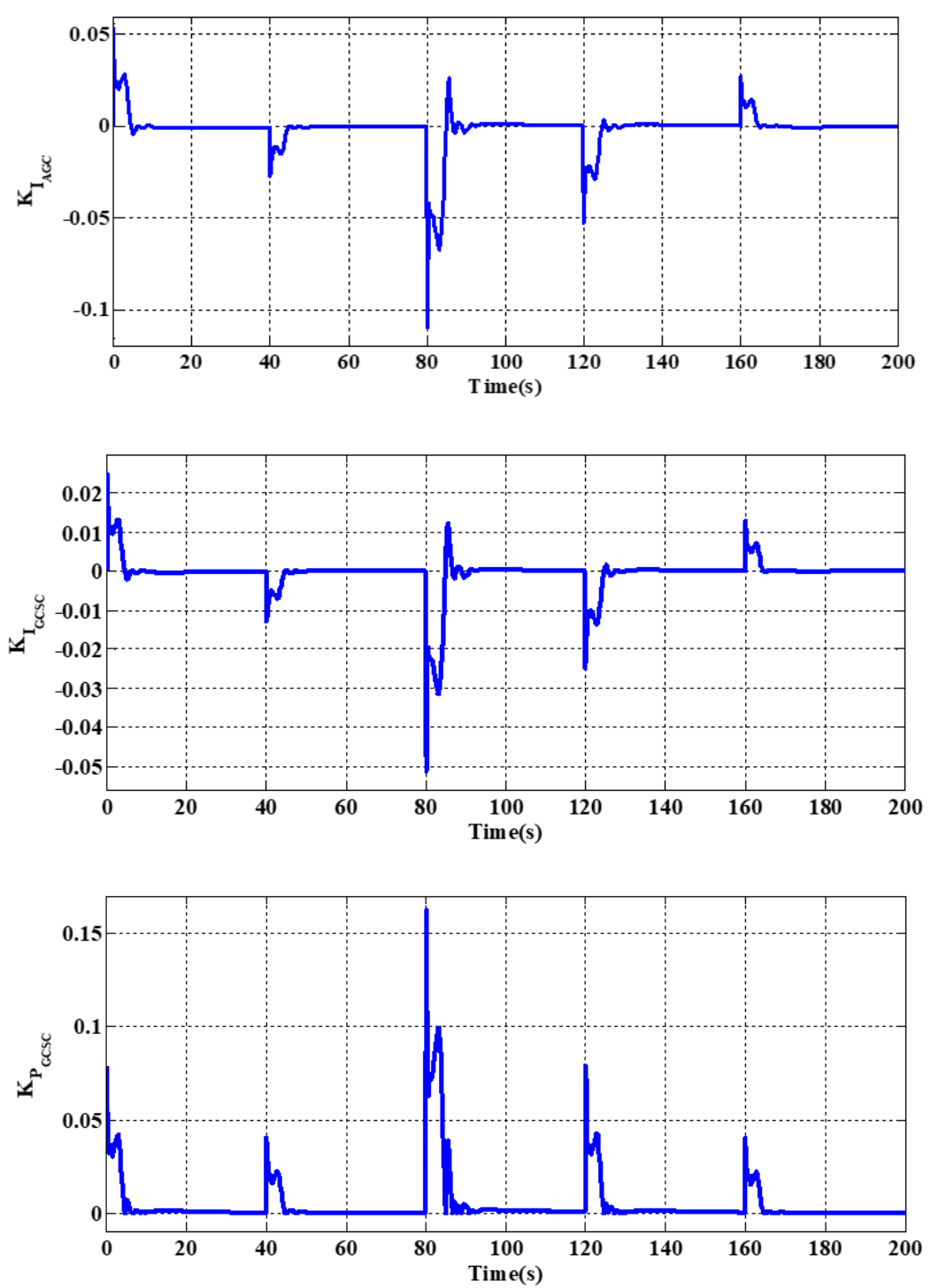

Fig. 10. The generated signals for GCSC and AGC from OFFT after RLP

\subsection{Third scenario: Sensitivity analysis}

This scenario examines robustness of the OFFT controller under $\pm 25 \%$ variation in synchronizing coefficient. In this regard, the $T_{12}$ (synchronizing coefficient) as an indicator of active tie-line power between the areas, changed drastically by $\pm 25 \%$ of nominal value regarding scenario 1 condition. Frequency deviations of the areas and tie-line power deviation are represented in Fig. 11 in a large time scale (100s). As seen, the OFFT is completely efficient for such a great deviation in the synchronizing coefficient. Fig. 12 shows the efficient deviation of 
the outputs of OFFT controller for online tuning of the AGC and GCSC gains in this scenario. It should be noted that, as governor time constant is known as another important index for sensitivity analysis and robustness examination [2]; herein, same sensitivity analysis is repeated for governor time constant of steam turbine $\left(T_{s g}\right)$. The results showed that the designed controller is completely robust for the $\pm 25 \%$ variation in $T_{s g}$ and the results are same for deviations in this time constant.
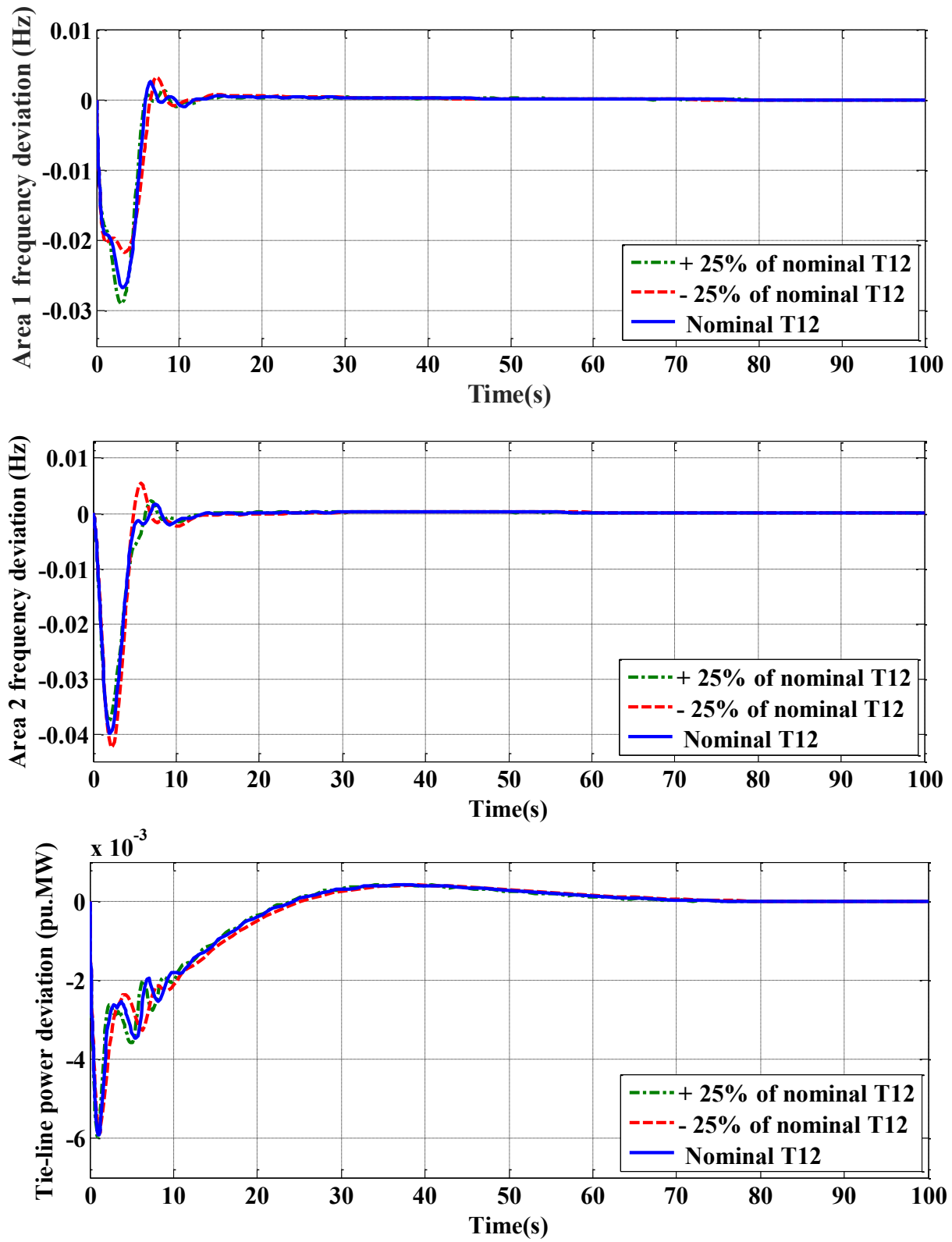

Fig. 11. Frequency and tie-line power deviations after $\pm 25 \%$ deviation in $T_{12}$ 

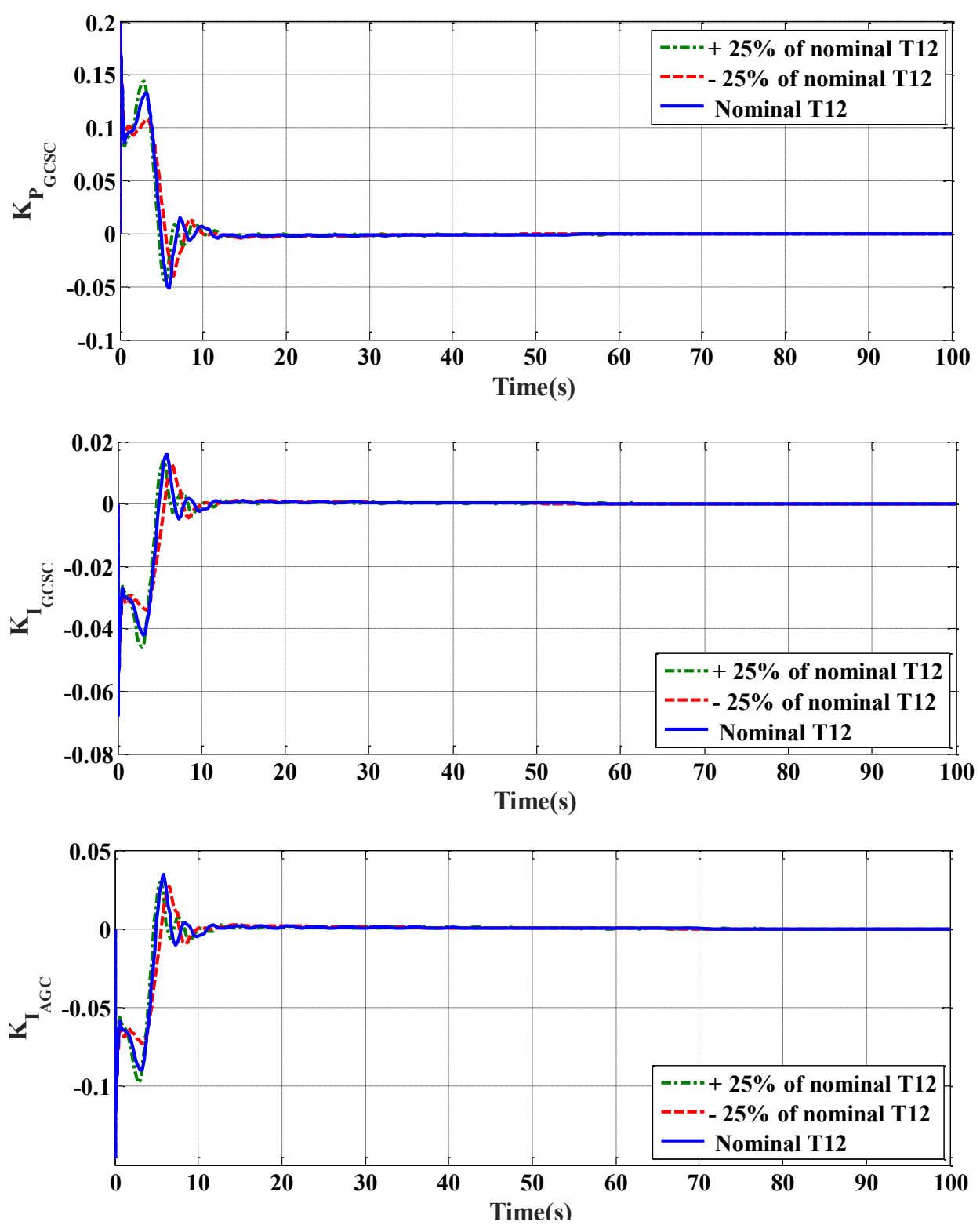

Fig. 12. The generated signals for GCSC and AGC from OFFT after $\pm 25 \%$ deviation in $T_{12}$

\section{Conclusion}

In this article, frequency performance of a multi-area power system enhanced through a coordination between GCSC and AGC loop. The coordination was established by an optimized fuzzy fine-tuning approach which modified the integral and proportional gains in classic controllers dynamically and in an online manner. Performance of the novel GCSC-AGC coordinated controller has been verified on the realistic interconnected multi-area power system 
considering GRC and GDB nonlinearities. It was demonstrated that the designed OFFT controller has better performance in comparison with a wide range of optimization methods known as GA, IPSO, $\mathrm{ACO}, \mathrm{ABC}$, and $\mathrm{SCA}$ in terms of damping ratio, pick overshoot and settling time. Also, the sensitivity analysis showed that the designed controller is robust against deviations in synchronizing coefficient.

In future, the work can be further extended from the following aspects. (i) Coordination between two different series FACTS devices in a multi-area power system (more than two areas) can be done by the proposed controller. (ii) Presence of renewable energy sources like wind farms in load frequency control, and their coordination with FACTS could be included to get more comprehensive results. (iii) Design process of another type of online coordinator known as artificial neural network coordinator could be useful to compare the results with the fuzzy coordinator in an LFC system. (iv) Impact of different size of GCSC on the LFC of power system can be investigated.

\section{References}

[1] H. Bevrani, Robust Power System Frequency Control, Springer, New York, USA, second edition, 2014.

[2] S. Golshannavaz, R. Khezri, M. Esmaeeli, P. L. Siano, "A two-stage robust-intelligent controller design for efficient LFC based on Kharitonov theorem and fuzzy logic," Journal of Ambient Intelligence Human Computing, pp. 1-10, 2017.

[3] H. Bevrani, and T. Hiyama, Intelligent Automatic Generation Control. New York: CRC, Apr. 2011.

[4] M. Datta, and T. Senjyu, "Fuzzy control of distributed PV inverters/energy storage systems/electric vehicles for frequency regulation in a large power system," IEEE Transactions on Smart Grid, vol. 4, no. 1, pp. 479 - 488, 2013.

[5] A. Oshnoei, R. Khezri, M. Ghaderzadeh, H. Parang, S. Oshnoei, and M. Kheradmandi, "Application of IPSO algorithm in DFIG-based wind turbines for efficient frequency control of multi-area power systems," Smart Grids Conference (SGC), 2017.

[6] W. Tasnin, and L.C. Saikia, "Performance comparison of several energy storage devices in deregulated AGC of a multi-area system incorporating geothermal power plant," IET Renewable Generation Power," vol. 12, iss. 7, pp. $761-772,2018$.

[7] R. Khezri, A. Oshnoei, M.T. Hagh, and SM. Muyeen, "Coordination of Heat Pumps, Electric Vehicles and AGC for Efficient LFC in a Smart Hybrid Power System via SCA-Based Optimized FOPID Controllers," Energies. vol. 11, 2018.

[8] K. Zare, M. T. Hagh, and J. Morsali, "Effective oscillation damping of an interconnected multi-source power system with automatic generation control and TCSC," Int. J. Electr. POWER ENERGY Syst., vol. 65, pp. 220- 
230, 2015.

[9] A. D. Falehi and A. Mosallanejad, "Neoteric HANFISC - SSSC Based on MOPSO Technique Aimed at Oscillation Suppression of Interconnected Multi - Source Power Systems," IET Generation, Transmission \& Distribution, vol. 10, no. 7, pp. 1728-1740, 2016.

[10] M. Nandi, C. K. Shiva, and V. Mukherjee, “ TCSC based automatic generation control of deregulated power system using quasi-oppositional harmony search algorithm," Engineering Science and Technology, an International Journal, vol. 20, no. 4, pp. 1380-1395, 2017.

[11] T. S. Gorripotu, R. K. Sahu, and S. Panda, "AGC of a multi-area power system under deregulated environment using redox flow batteries and interline power flow controller," Engineering Science and Technology, an International Journal, vol. 18, no. 4, pp. 555-578, 2015.

[12] P. C. Pradhan, R. K. Sahu, and S. Panda, "Firefly algorithm optimized fuzzy PID controller for AGC of multiarea multi-source power systems with UPFC and SMES," Engineering Science and Technology, an International Journal, vol. 19, no. 1, pp. 338-354, 2016.

[13] P. Dahiya, V. Sharma, and R. Naresh, "Optimal sliding mode control for frequency regulation in deregulated power systems with DFIG-based wind turbine and TCSC-SMES," Neural Computing and Applications, pp. 118, 2017.

[14] P. Bhatt, R. Roy, and S. Ghoshal, "Comparative performance evaluation of SMES-SMES, TCPS-SMES and SSSC-SMES controllers in automatic generation control for a two-area hydro-hydro system," International Journal of Electrical Power \& Energy Systems, vol. 33, no. 10, pp. 1585-1597, 2011.

[15] J. Morsali, K. Zare, and M. T. Hagh, "MGSO optimised TID-based GCSC damping controller in coordination with AGC for diverse-GENCOs multi-DISCOs power system with considering GDB and GRC non-linearity effects," IET Generation, Transmission \& Distribution, vol. 11, no. 1, pp. 193-208, 2017.

[16] I. Chidambaram and B. Paramasivam, "Optimized load-frequency simulation in restructured power system with redox flow batteries and interline power flow controller," International Journal of Electrical Power \& Energy Systems, vol. 50, pp. 9-24, 2013..

[17] S. Padhan, R. K. Sahu, and S. Panda, "Automatic generation control with thyristor controlled series compensator including superconducting magnetic energy storage units," Ain Shams Engineering Journal, vol. 5, no. 3, pp. 759-774, 2014.

[18] M. Deepak and R. J. Abraham, "Load following in a deregulated power system with Thyristor Controlled Series Compensator," International Journal of Electrical Power \& Energy Systems, vol. 65, pp. 136-145, 2015.

[19] J. Morsali, K. Zare, and M. T. Hagh, "Applying fractional order PID to design TCSC-based damping controller in coordination with automatic generation control of interconnected multi-source power system," Engineering Science and Technology, an International Journal, vol. 20, no. 1, pp. 1-17, 2017.

[20] P. Bhatt, S. P. Ghoshal, and R. Roy, "Electrical Power and Energy Systems Load frequency stabilization by coordinated control of Thyristor Controlled Phase Shifters and superconducting magnetic energy storage for three types of interconnected two-area power systems," International Journal of Electrical Power \& Energy Systems, vol. 32, no. 10, pp. 1111-1124, 2010.

[21] R. K. Sahu, T. S. Gorripotu, and S. Panda, "A hybrid DE-PS algorithm for load frequency control under deregulated power system with UPFC and RFB," Ain Shams Engineering Journal, vol. 6, no. 3, pp. 893-911, 2015.

[22] R. Abraham, D. Das, and A. Patra, "Effect of TCPS on oscillations in tie-power and area frequencies in an interconnected hydrothermal power system," IET Generation, Transmission \& Distribution, vol. 1, no. 4, pp. 632-639, 2007.

[23] R. Shankar, S. Pradhan, S. Sahoo, and K. Chatterjee, "GA based improved frequency regulation characteristics for thermal-hydro-gas \& DFIG model in coordination with FACTS and energy storage system," in Recent Advances in Information Technology (RAIT), 2016 3rd International Conference on, 2016, pp. 220-225.

[24] E. H. Watanabe, L. De Souza, F. De Jesus, J. Alves, and A. Bianco, "GCSC-gate controlled series capacitor: a new facts device for series compensation of transmission lines," in Transmission and Distribution Conference and Exposition: Latin America, 2004 IEEE/PES, 2004, pp. 981-986. 
[25] A. Safari and N. Rezaei, "Towards an extended power system stability: an optimized GCSC-based inter-area damping controller proposal," International Journal of Electrical Power \& Energy Systems, vol. 56, pp. 316324, 2014.

[26] H. A. Mohammadpour and E. Santi, "Modeling and control of gate-controlled series capacitor interfaced with a DFIG-based wind farm," IEEE Transactions on Industrial Electronics, vol. 62, no. 2, pp. 1022-1033, 2015.

[27] H. Shayeghi, H. Shayanfar, and A. Jalili, "Load frequency control strategies: A state-of-the-art survey for the researcher," Energy Conversion and management, vol. 50, no. 2, pp. 344-353, 2009.

[28] S. K. Pandey, S. R. Mohanty, and N. Kishor, "A literature survey on load-frequency control for conventional and distribution generation power systems," Renewable and Sustainable Energy Reviews, vol. 25, pp. 318-334, 2013.

[29] R. K. Sahu, S. Panda, and U. K. Rout, "DE optimized parallel 2-DOF PID controller for load frequency control of power system with governor dead-band nonlinearity," International Journal of Electrical Power \& Energy Systems, vol. 49, pp.19-33, 2013.

[30] M. Kothari, P. Satsangi, and J. Nanda, "Sampled-data automatic generation control of interconnected reheat thermal systems considering generation rate constraints," IEEE Transactions on Power Apparatus and Systems, PAS-100, p. 2334-2342, 1981.

[31] K. Parmar, S. Majhi, and D. Kothari, "Load frequency control of a realistic power system with multi-source power generation," International Journal of Electrical Power \& Energy Systems, vol. 42, pp. 426-433, 2012.

[32] S. Mirjalili, "SCA: a sine cosine algorithm for solving optimization problems," Knowledge-Based Systems, vol. 96, pp. 120-133, 2016.

[33] A. Oshnoei, R. Khezri, SM. Muyeen, and F. Blaabjerg, "On the contribution of wind farms in automatic generation control: review and new control approach," Applied Sciences, vol. 8, pp. 1-23.

[34] D. Karaboga and B. Basturk, "A powerful and efficient algorithm for numerical function optimization: artificial bee colony (ABC) algorithm," Journal of global optimization, vol. 39, no. 3, pp. 459-471, 2007.

[35] D. Karaboga, "An idea based on honey bee swarm for numerical optimization," Technical report-tr06, Erciyes university, engineering faculty, computer engineering department 2005.

[36] J. Kennedy, "Particle swarm optimization," in Encyclopedia of machine learning: Springer, 2011, pp. 760-766.

[37] J. H. Holland, “Genetic algorithms," Scientific American, vol. 267, no. 1, pp. 66-73, 1992.

[38] M. Dorigo, V. Maniezzo, and A. Colorni, "Ant system: optimization by a colony of cooperating agents," IEEE Transactions on Systems, Man, and Cybernetics, Part B (Cybernetics), vol. 26, iss. 1, pp. 29-41, 1996.

[39] F. D'Andreagiovanni, J. Krolikowski, and J. Pulaj, "A fast hybrid primal heuristic for multiband robust capacitated network design with multiple time periods," Applied Soft Computing, vol. 26, pp. 497-507, 2015.

[40] L.M. Gambardella, R. Montemanni, D. Weyland, "Coupling ant colony systems with strong local searches," European Journal Operational Research, vol. 220, pp. 831-843, 2012.

[41] A. Oshnoei, M. T. Hagh, R. Khezri, B. Mohammadi-Ivatloo, "Application of IPSO and fuzzy logic methods in electrical vehicles for efficient frequency control of multi-area power systems," Iranian Conference on Electrical Engineering (ICEE), pp. 1349-1354, 2017.

[42] R. Khezri, S. Golshannavaz, S. Shokoohi, and H. Bevrani, "Fuzzy Logic Based Fine-tuning Approach for Robust Load Frequency Control in a Multi-area Power System," Electric Power Components Syst., vol. 44, no. 18, pp. 2073-2083, 2016.

[43] R. Khezri, S. Golshannavaz, R. Vakili, and B. Memar-Esfahani, "Multi-layer under frequency load shedding in back-pressure smart industrial microgrids," Energy, vol. 132, pp. 96-105, 2017.

[44] H.A. Mohammadpour, and E. Santi, "Modeling and control of gate-controlled series capacitor interfaced with a DFIG-based wind farm," IEEE Transaction on Industrial Electronics, vol. 62, iss. 2, pp. 1022-1033, 2015.

[45] M.R.A. Pahlavani, and H.A. Mohammadpour, "Damping of sub-synchronous resonance and low-frequency power oscillation in a series-compensated transmission line using gate-controlled series capacitor," Electric Power Systems Research, vol. 81, pp. 308-317, 2011. 
NomenClature

\begin{tabular}{|c|c|c|c|}
\hline Parameter & Description & Parameter & Description \\
\hline $\begin{array}{l}R_{t h,} R_{h y d} \\
\text { and } R_{g}\end{array}$ & $\begin{array}{l}\text { Governor speed regulation } \\
\text { parameters of thermal, hydro and gas } \\
\text { units }\end{array}$ & $\begin{array}{l}P F_{\text {th }} P F_{\text {hyd }} \\
\text { and } P F_{g}\end{array}$ & $\begin{array}{l}\text { Participation factors of thermal, gas, } \\
\text { and hydro units }\end{array}$ \\
\hline$T_{s g}$ & $\begin{array}{l}\text { Governor time constant of steam } \\
\text { turbine }\end{array}$ & $B_{g}$ & Time constant of the valve positioner \\
\hline$T_{t}$ & Steam turbine time constant & $T_{g h}$ & Hydro turbine governor time constant \\
\hline$T_{w}$ & $\begin{array}{l}\text { Starting time constant of water in } \\
\text { hydro turbine }\end{array}$ & $T_{c d}$ & $\begin{array}{l}\text { Compressor discharge volume time } \\
\text { constant }\end{array}$ \\
\hline$K_{r}$ & Steam turbine reheat constant & $C_{g}$ & Gas turbine valve positioner \\
\hline$T_{r}$ & Steam turbine reheat time constant & $T_{f}$ & Gas turbine fuel time constant \\
\hline$T_{p s 1} T_{p s 2}$ & Power system time constants & $T_{c r}$ & $\begin{array}{l}\text { Gas turbine combustion reaction time } \\
\text { delay }\end{array}$ \\
\hline$X_{g}$ & $\begin{array}{l}\text { Lead time constant of gas turbine } \\
\text { governor }\end{array}$ & $T_{r s}$ & $\begin{array}{l}\text { Hydro turbine speed governor reset } \\
\text { time }\end{array}$ \\
\hline$Y_{g}$ & $\begin{array}{l}\text { Lag time constant of gas turbine } \\
\text { governor }\end{array}$ & $T_{12}$ & Synchronizing coefficient \\
\hline$B_{1,} B_{2}$ & Frequency bias coefficients & $K_{p s 1,} K_{p s 2}$ & Power system gains \\
\hline
\end{tabular}

